\title{
Factors associated with metabolic syndrome among the elderly in the northeast of Brazil
}

Fabiana Lucena Rocha'

Rômulo Lustosa Pimenteira de Meloº Tarciana Nobre de Menezes ${ }^{3}$

\section{Abstract}

Objective: To determine the prevalence of metabolic syndrome (MS) and associated factors in 348 elderly residents of Campina Grande, Paraíba. Method: A household survey and clinical/laboratory assessment was conducted. The diagnosis of MS was based on the criteria of the Third Report of the National Cholesterol Education Program Expert Panel on the Detection, Evaluation and Treatment of High Blood Cholesterol in Adults (NCEP-ATP III). The association between MS and socio-demographic factors, health status and lifestyle habits was investigated. The crude and adjusted prevalence ratios were obtained by Poisson regression. Variables with a significance lower than or equal to 0.2 $(20 \%)$ were tested in a multivariate model. A $p$ value $\leq 0.05$ was adopted for the acceptance of the associations in the final model. Results: MS was more prevalent among women $(64.7 \%)$ and those with heart trouble. It was also found that, specifically for women, there was a higher prevalence of MS among those with osteoarthritis. Conclusion: The higher prevalence of MS among women and the association of MS with osteoarthritis in this group deserves attention, as this condition can cause functional limitation, affecting the quality of life of the elderly.

\footnotetext{
Universidade Federal de Campina Grande, Unidade Acadêmica Escola Técnica de Saúde de Cajazeiras. Cajazeiras, Paraíba, Brasil.

2 Universidade Federal da Paraíba, Centro de Ciências Humanas, Letras e Artes, Programa de Pós-graduação em Psicologia Social. João Pessoa, Paraíba, Brasil.

3 Universidade Estadual da Paraíba, Programa de Pós-graduação em Saúde Pública, Departamento de
} Fisioterapia. Campina Grande, Paraíba, Brasil.

Research funding: Conselho Nacional de Desenvolvimento Científico e Tecnológico (National Council for Scientific and Technological Development) $(\mathrm{CNPq})$ and Ministério da Ciência e Tecnologia (Ministry of Science and Technology) (MCT). Process No. 479579/2007-5. Bid Application Process MCT/CNPq 15/2007.

Keywords: Metabolic Syndrome. Elderly. Chronic Disease. 


\section{INTRODUCTION}

Noncommunicable chronic diseases such as heart disease, strokes, diabetes mellitus and cancer account for two-thirds of total global deaths. This is mainly due to an aging population and the clustering of risk factors associated with globalization and urbanization ${ }^{1}$.

The physiological changes that occur during the aging process favor the emergence of alterations that make up metabolic syndrome (MS), such as high blood pressure, the abnormal deposition of abdominal fat, changes in lipid levels and, in some cases, blood sugar levels ${ }^{2,3}$. These changes may be associated with a prothrombotic and proinflammatory state ${ }^{3,4}$.

Due to the chronicity of the condition, early identification and preventive intervention against risk factors is important in individuals with MS or its components to reduce morbidity and mortality and promote a change in lifestyle $e^{3,4}$.

In a systematic review, which aimed to determine the prevalence of metabolic syndrome in the elderly, the lowest overall prevalence was $23.2 \%$ among elderly Chinese individuals, while the highest prevalence recorded was $67.9 \%$ in Mexican elderly persons. Studies have shown a higher prevalence in women and among older elderly persons ${ }^{5}$.

Vidigal et al. ${ }^{6}$, in a systematic review of different MS prevalence rates in Brazil, found that such rates varied depending on the characteristics of the groups studied, based on the ethnic, cultural and epidemiological variability of the country. The authors found that the overall weighted average for the prevalence of MS was between 28.9 and $29.6 \%$, according to the criteria used to define metabolic syndrome. Specific data on the prevalence of this condition among the elderly population is still scarce in Brazilian studies.

Epidemiological studies on adults and elderly persons have found that MS is associated with age, gender, educational level ${ }^{3,7}$, race or ethnicity, hypercholesterolemia, high concentrations of C-reactive protein (CRP), microalbuminuria and hyperinsulinemia ${ }^{7}$. In addition, MS impacts health spending, as its components lead to chronic conditions, burdening the health system ${ }^{8}$. This makes it important to ensure the adequate treatment and control of risk factors, as the chronicity of their components causes irreversible consequences?.

Given the importance of MS as a risk factor for cardiovascular disease, and as differences in the different population groups surveyed make it difficult to compare results, there is a clear need for further studies on the prevalence of MS, not only among the general population, but especially among elderly people in Brazil. Therefore, the present study aimed to determine the prevalence of metabolic syndrome and associated factors in elderly persons enrolled in the Estratégia Saúde da Família (the Family Health Strategy) in a municipality in the northeast of Brazil.

\section{METHOD}

This study is part of a larger study entitled "Multidimensional evaluation of the health of elderly persons attended by the Family Health Strategy in the city of Campina Grande, Paraíba, and degree of satisfaction with the services offered." A crosssectional home-based study was performed.

The sample was calculated by estimating the prevalence of outcomes of at least $25 \%$. To calculate the sample, the following equation was used: $\left\{\left[\mathrm{E}^{2} \mathrm{x}\right.\right.$ $p(1-p)] \times c\} / A^{2}$, where $E$ is the level of confidence (1.96), $\mathrm{c}$ is the sample correction coefficient (2.1) for sample by clustering, and $\mathrm{A}$ is the acceptable precision for the estimated prevalence $(6 \%)$. The sample was proportional to each health district of the city and constituted 420 elderly persons. Elderly individuals who did not attend blood collection sessions were excluded from the study, resulting in a sample of 348 elderly persons. A confidence interval of $95 \%$ was applied.

The sampling was carried out in multiple stages using clusters. The primary sampling units were six health districts from the city, from which six Basic Family Health Units (BFHU) were randomly drawn. The number of registered elderly persons in each unit was identified and random sampling was performed using a list with all their names. After every elderly person selected for interview the next four names on the list were skipped and the following elderly person selected. This interval was defined by the ratio between the total number of individuals registered and the number selected to participate in 
the interview. This step was repeated successively for improved distribution and to ensure that the entire list was covered.

Individuals aged 60 or older of both genders were selected for the sample. Excluded from the study were elderly persons with a severely debilitated clinical state without treatment possibilities, namely those in the terminal stage of disease. Elderly persons without assistants, if assistance was required when answering questions; and those who were absent during the field research in the catchment area of the $\mathrm{BFHU}$ where they were registered were also removed from the sample. Those excluded were replaced by the next elderly person in the systematic selection.

Data was collected between August 2009 and May 2010 by three pairs of interviewers who were trained and calibrated in the pilot study. After signing a Free and Informed Consent Form the participants were interviewed at home and were instructed to attend the BFHU at a predetermined time and date for the collection of blood for biochemical assessment. They were also told to fast for 12 hours before blood collection.

The diagnosis of MS was based on the criteria of the revised Third Report of the National Cholesterol Education Program Expert Panel on Detection, Evaluation and Treatment of High Blood Cholesterol in Adults (NCEP-ATP III ${ }^{10}$, which involves the presence of three or more of the following factors: abdominal obesity, hypertriglyceridemia, low levels of high density lipoproteins (HDL), hypertension and high fasting glucose $e^{4}$. Abdominal obesity was verified by abdomen circumference (AC), measured using the techniques of Callaway et $\mathrm{a}^{11}$. Biochemical evaluation consisted of the analysis of lipid profile and fasting glucose.

In addition to this information, data was collected on gender, skin color/ethnicity (white or non-white), socioeconomic status (A/B, C, D/E), marital status (single, married, widowed, separated), age group (60 to 69 years, 70-79 years or 80 years or more), self-rated health, morbidities (heart problems, osteoporosis, osteoarthritis, chronic lung disease, cancer), smoking (never smoked, smoker, ex-smoker) and regularly practiced exercise (yes, no).

Socioeconomic status was verified by the Critério de Classificação Econômica Brasil of the Associação
Brasileira de Empresas de Pesquisa (ABEP) (the Brazilian Economic Classification Criterion of the Brazilian Association of Research Companies) ${ }^{12}$ which consists of information on the educational level of the elderly person and family ownership of consumer goods. Each piece of information is related to points which are added to generate a score on the economic stratification scale, corresponding to the economic class to which the elderly person belongs. The elderly persons were classified as belonging to class A/B (17-34 points), C (11-16 points) and D/E (0 to 10 points).

For the self-reported health variable, the elderly individuals were asked how they considered their health and, based on the Likert scale, responded excellent, very good, good, fair and poor. The variable was dichotomized into good (excellent, very good, good) or poor (fair and poor) self-evaluation of health. For the physical exercise variable, an elderly person was considered physically active if he or she regularly performed physical activity for at least thirty minutes three times a week or more ${ }^{13,14}$.

The data was tabulated and analyzed using Poisson regression, with the calculation of $\operatorname{Exp}(B)$ interpreted as the prevalence ratio $\left(\mathrm{PR}_{\text {gross }}\right.$ for bivariate and $\mathrm{PR}_{\text {adjusted }}$ for the multivariate model) with $95 \%$ confidence intervals. For this, the robust estimator in the covariance matrix was used to obtain more robust standard errors. In bivariate analysis, variables with a significance of lower than or equal to $0.2(20 \%)$ were tested in a multivariate model. Finally, a moderation model was used to test the prevalence ratio $\left(\mathrm{RP}_{\text {controlled }}\right)$ between osteoarthritis and a change in MS based on gender. A value of $\mathrm{p}<0.05$ was adopted for the acceptance of the associations investigated in the multivariate and moderation models.

The study was approved by the Ethics Research Committee of the Universidade Estadual da Paraíba (Paraiba State University) (CAAE: 0228.0.133.000-08).

\section{RESULTS}

A total of 348 elderly persons participated in the study, of whom $67.8 \%$ were women. The age of the participants varied from 60 to 104 years, with a mean of $71.57(+9.1)$ years. The results of bivariate analysis 
showed the prevalence of MS and its association with the variables studied. There was a statistically significant association between MS and gender and MS and reports of osteoarthritis. The prevalence of MS was greater among women (PRgross=1.75; CI95\% $=1.37-2.25)$ and among elderly persons who reported suffering from osteoarthritis (PRgross=1.26; CI95\% $=1.05-1.50$ ) (Table 1).

Variables included in the multivariate model were those with a significance of less than or equal to 0.2 in bivariate analysis. These were sex, skin color/ ethnicity, heart problems, osteoporosis, osteoarthritis and smoking. Analysis of the results presented in Table 2 shows that only the variables gender and reports of a heart condition were statistically significant for MS. The highest prevalence of MS was found among women (PRadjusted $=1.71,95 \%$ CI 1.31 to 2.22) and among elderly persons who reported a heart problem (PRadjusted=1.20; 95\% CI = 1-1,44). In the multivariate model osteoarthritis ceased to have a significant effect. A third model was therefore created to verify that the initial effect of the osteoarthritis variable was due to gender.

An interaction term was therefore created between the variables osteoarthritis and gender (an interaction term is performed by multiplying the two variables) 15 and inserted in the multivariate regression together with the variables osteoarthritis and gender. The results showed that only the interaction and the osteoarthritis variable had a significant effect $(\mathrm{p}<0.05)$, suggesting the lack of significance of osteoarthritis presented in the multivariate model was due to the variable gender.

Table 3 presents a moderation model between osteoarthritis and metabolic syndrome, verifying that the prevalence ratio of osteoarthritis (PRcontrolled) changes depending on gender. The results show that among elderly women only, the osteoarthritis variable demonstrated statistically significant results for the occurrence of MS (PRcontrolled=1.23; 95\% $\mathrm{CI}=1.03$ to 1.46$)$.

Table 1. Bivariate Poisson Regression (PRgross) in relation to the outcome of metabolic syndrome and associated factors. Campina Grande, Paraíba, 2010.

\begin{tabular}{|c|c|c|c|c|c|}
\hline & \multicolumn{5}{|c|}{ Metabolic Syndrome } \\
\hline & No & Yes & $\mathrm{RP}_{\text {gross }}$ & CI $95 \%$ & $p$ \\
\hline & $\mathrm{n}(\%)$ & $\mathrm{n}(\%)$ & & & \\
\hline \multicolumn{6}{|l|}{ Gender } \\
\hline Male & $69(61.6)$ & $43(38.4)$ & & & \\
\hline Female & $77(32.6)$ & $159(67.4)$ & 1.75 & $1.37-2.25$ & $<0.01$ \\
\hline \multicolumn{6}{|c|}{ Skin color/ethnicity } \\
\hline White & $63(37.5)$ & $105(62.5)$ & & & \\
\hline Non-white & $83(46.1)$ & $97(53.9)$ & 1.16 & $0.97-1.39$ & 0.10 \\
\hline \multicolumn{6}{|c|}{ Socio-economic level } \\
\hline $\mathrm{A} / \mathrm{B}$ & $71(43.6)$ & $92(56.4)$ & & & \\
\hline $\mathrm{C}$ & $61(39.9)$ & $92(60.1)$ & 1.17 & $0.77-1.49$ & 0.69 \\
\hline $\mathrm{D} / \mathrm{E}$ & $14(43.8)$ & $18(56.3)$ & 0.98 & $0.81-1.43$ & 0.41 \\
\hline \multicolumn{6}{|l|}{ Marital status } \\
\hline Single & $11(50.0)$ & $11(50.0)$ & & & \\
\hline Married & $97(47.7)$ & $107(52.5)$ & 1.05 & $0.68-1.62$ & 0.83 \\
\hline Widowed & $29(28.2)$ & $74(71.8)$ & 1.44 & $0.93-2.22$ & 0.21 \\
\hline Separated & $9(47.4)$ & $10(52.6)$ & 1.05 & $0.58-1.91$ & 0.87 \\
\hline \multicolumn{6}{|l|}{ Age group } \\
\hline 80 years or more & $26(44.8)$ & $32(55.2)$ & & & \\
\hline 70 to 79 years & $53(46.1)$ & $62(53.9)$ & 0.97 & $0.73-1.30$ & 0.87 \\
\hline
\end{tabular}


continued from table 1

\begin{tabular}{|c|c|c|c|c|c|}
\hline & \multicolumn{5}{|c|}{ Metabolic Syndrome } \\
\hline & No & Yes & $\mathrm{RP}_{\text {gross }}$ & CI $95 \%$ & $p$ \\
\hline & $\mathrm{n}(\%)$ & $\mathrm{n}(\%)$ & & & \\
\hline 60 to 69 years & $67(38.3)$ & $108(61.7)$ & 1.12 & $0.86-1.45$ & 0.40 \\
\hline \multicolumn{6}{|l|}{ Self-related health } \\
\hline Good self-evaluation & $48(41.0)$ & $69(59.0)$ & & & \\
\hline Poor self-evaluation & $98(42.4)$ & $133(57.6)$ & 0.97 & $0.81-1.18$ & 0.80 \\
\hline \multicolumn{6}{|l|}{ Heart problems } \\
\hline No & $115(44.4)$ & $144(55.6)$ & & & \\
\hline Yes & $31(35.8)$ & $58(65.2)$ & 1.17 & $0.97-1.4$ & 0.11 \\
\hline \multicolumn{6}{|l|}{ Osteoporosis } \\
\hline No & $126(43.8)$ & $162(56.3)$ & & & \\
\hline Yes & $20(33.3)$ & $40(66.7)$ & 1.19 & $0.97-1.46$ & 0.10 \\
\hline \multicolumn{6}{|l|}{ Osteoarthritis } \\
\hline No & $105(46.7)$ & $120(53.3)$ & & & \\
\hline Yes & $41(33.3)$ & $82(66.7)$ & 1.26 & $1.05-1.50$ & 0.01 \\
\hline \multicolumn{6}{|l|}{ Chronic lung disease } \\
\hline No & $135(41.8)$ & $188(58.2)$ & & & \\
\hline Yes & $11(44.0)$ & $14(56.0)$ & 0.96 & $0.67-1.39$ & 0.85 \\
\hline \multicolumn{6}{|l|}{ Cancer } \\
\hline No & $142(42.3)$ & $194(57.7)$ & & & \\
\hline Yes & $4(33.3)$ & $8(66.7)$ & 0.15 & $0.77-1.74$ & 0.49 \\
\hline \multicolumn{6}{|l|}{ Smoker } \\
\hline Never smoked & $57(37.0)$ & $97(63.0)$ & & & \\
\hline Smoker & $20(46.5)$ & $23(53, .5)$ & 0.85 & $0.62-1.15$ & 0.29 \\
\hline Ex-Smoker & $69(45.7)$ & $82(54.3)$ & 0.96 & $0.71-1.04$ & 0.12 \\
\hline \multicolumn{6}{|c|}{ Regular physical exercise } \\
\hline No & $103(42.2)$ & $141(57.8)$ & & & \\
\hline Yes & $43(41.1)$ & $61(58.7)$ & 0.98 & $0.80-1.18$ & 0.80 \\
\hline
\end{tabular}

Table 2. Multivariate Poisson Regression (PRadjusted) in relation to the outcome of metabolic syndrome and associated factors. Campina Grande, Paraíba, 2010.

\begin{tabular}{llll}
\hline & $\mathrm{RP}_{\text {adiusted }}$ & $\mathrm{CI}$ 95\% & $p$ \\
\hline Gender & & - & \\
Male & & $1.3-2.22$ & $<0.01$ \\
Female & 1.71 & & \\
Skin color/ethnicity & & - & 0.28 \\
White & & $0.92-1.31$ & \\
Non-white & 1.10 & & 0.05 \\
Heart problems & & -- & \\
No & & $1.00-1.44$ & \\
Yes & 1.20 & & \\
\hline
\end{tabular}


continued from table 2

\begin{tabular}{llll}
\hline Osteoporosis & & & \\
No & 0.92 & -- & $0.75-1.15$ \\
Yes & & & \\
\hline Osteoarthritis & & -- & 0.14 \\
No & 1.15 & $0.96-1.38$ & \\
Yes & & & \\
\hline Smoker & & -- & 0.61 \\
Never smoked & 0.92 & $0.68-1.26$ & 1.16 \\
Smoker & 0.96 & $0.80-1.16$ & \\
Ex-Smoker & & &
\end{tabular}

Table 3. Poisson Regression Analysis (PRcontrolled). Campina Grande. Paraíba. 2010.

\begin{tabular}{lllll}
\hline Gender & Osteoarthritis & $\mathrm{RR}_{\text {Pcontrolled }}$ & $\mathrm{CI} 95 \%$ & $P$ \\
\hline Male & No & & & \\
& Yes & 0.66 & $0.32-1.37$ & 0.27 \\
Female & No & & & \\
& Yes & 1.23 & $1.03-1.46$ & 0.02 \\
\hline
\end{tabular}

\section{DISCUSSION}

A SSM comprises the pathophysiological changes related to the metabolic disorders that have a major influence on the life of the elderly, due to the impairment caused by the limitations imposed by its components. These can directly impact the quality of life of elderly individuals through the emergence of associated chronic conditions ${ }^{16}$.

Among the main factors associated with MS are obesity, diabetes mellitus, cardiovascular diseases, renal diseases, osteoarticular diseases and hypertension. The combination of these factors and metabolic syndrome among the elderly has so far been investigated both in Brazil ${ }^{9,16,17}$ and in other countries $^{18,19}$ in an incipient manner, as the studies in question considered heterogeneous age samples. There is therefore a lack of scientific evidence about the role of MS in different health outcomes in the elderly population.

In the present study, there were no significant associations between MS and socioeconomic status, marital status, age group, health self-assessment, chronic pulmonary disease, reports of cancer or regular physical exercise. However, surveys of the elderly have described the importance of some of these variables as risk factors for $\mathrm{MS}^{3,9,17}$.

It is therefore advisable to encourage health education strategies for self-care, including the adoption of a healthy diet and changes in lifestyle, such as stopping smoking, for the prevention of the individual components of MS.

The results of multivariate analysis showed a higher prevalence of MS in women and elderly persons who reported heart problems. Other studies of the elderly have also found a higher prevalence of MS among women with ${ }^{20}$ and without cardiac problems ${ }^{21}$ and differences btween genders when considering the components of the syndrome either in isolation or in combination with other cardiovascular risk factors ${ }^{22}$.

This higher prevalence of MS among elderly women may be due to the fact they have a greater deposition of body fat, which, in addition to the reduction in estrogen levels that comes with advancing age, influences the onset of dyslipidemia and abdominal $\mathrm{fat}^{23}$. The termination of the production of estrogen causes physiological changes, raises levels of lipids and provides a risk for certain diseases. It can therefore 
impact on health, compromising the quality of life of women ${ }^{24}$.

As the deposition of body fat, hyperglycemia and dyslipidemia are significant for the involvement of MS, actions of prevention and control are encouraged, including physical exercise and the adoption of healthy eating habits, which impact on reducing weight and levels of lipids and glucose. Thus, in addition to preventive aspects, the evaluation of patients based on their metabolic profile, with early recognition of risk factors, is desirable to identify and treat patients at high cardiovascular and metabolic risk ${ }^{3}$.

The present study verified an association between heart problems and MS. In general, MS is associated with twice the risk for cardiovascular diseases such as myocardial infarction, strokes and cardiovascular mortality, as well as resulting in a 1.5 times greater risk for all-cause mortality ${ }^{3}$.

The relationship between the pathophysiology of MS and increased cardiovascular risk is not conclusive, but there is evidence that insulin resistance is the main factor behind the progression of the condition to hyperinsulinemia and hyperglycemia, causing peripheral vasoconstriction and sodium retention. Furthermore, the development of the pathophysiology of MS brings increased production of triglycerides, cholesterol, low density lipoprotein (LDL) and apolipoprotein $\mathrm{B}$, predisposing the individual to the onset of atherosclerosis, as well as hypertension and hyperlipidemia ${ }^{3}$.

A systematic review found that the components of MS are independent risk factors for the development of atherosclerotic cardiovascular disease. The diagnostic criteria of this syndrome are based on the principle that its risk factors can interact synergistically, or increase the risk of coronary artery disease and atherosclerosis ${ }^{16}$.

As the morbidity and mortality caused by these diseases have repercussions on the epidemiological profile of Brazil and, consequently, represent a financial cost to the health system, there is a need for monitoring and prevention of MS through intervention actions in the health sector and specific programs of the Sistema Único de Saúde, aimed at reducing risk factors through the control of obesity, regular physical exercise, improvements in the lipid and glucose profile and control of blood pressure levels.

The alteration in the prevalence ratio due to gender was observed in these results after the inclusion of the interaction term in the analysis, with the osteoarthritis variable found to have a significant effect on the presence of MS among women. Studies show that osteoarticular diseases, including osteoarthritis, are comorbidities that are associated with MS ${ }^{18,19}$. This is the most prevalent form of arthritis and a leading cause of disability in people aged 65 or more. Its symptoms appear after 40 years of age and affect more women than men after 50 years of age $e^{25}$.

It is believed that its relationship with MS is due to alterations in metabolism and inflammation, as the pathogenesis of the diseases involves common metabolic abnormalities, including low grade inflammatory conditions with the elevation of systemic inflammatory markers. There are clear pathogenic roles for inflammatory mediators such as tumor necrosis factor alpha (TNFalfa) and interleukin 1 beta (IL1 $\beta$ ) in both MS and osteoarthritis. Leptin, a pro-inflammatory hormone produced by macrophages in adipose tissue, is a key mediator of metabolic dysregulation associated with obesity and has also been associated with the pathogenesis of osteoarthritis ${ }^{18}$.

These findings are relevant because the chronic outcomes reported by the elderly are causes of functional limitations, which are common at this stage of life, yet preventable. In addition to the risk related to metabolic disorders and to the associated factors investigated here, the functional limitations caused by osteoarthritis, which greatly affects this age group, lead to an impaired quality of life and functional capacity.

The present study has some limitations that should be considered when analyzing the results, including sample loss due to the non-attendance of elderly persons for blood collection and the inability to establish the causality of the associations obtained, as the study has a cross-sectional design. The possibility of recall bias for the variables mentioned, in addition to survival bias, should be considered. These biases are common when working with the elderly and can reduce the strength of the associations. 


\section{CONCLUSION}

The association of metabolic syndrome with osteoarthritis among women suggests a need to focus more closely on prevention, considering the differences observed between the genders and the prevalence and the severity of the associated problems.

There are many issues involving metabolic syndrome that remain unclear, including the importance of early diagnosis, studies that compare the difficulty of using different diagnostic criteria, the characteristics of the population and the different clinical aspects involving the syndrome in both the

\section{REFERENCES}

1. World Health Organization. World Health Statistics. Geneva: WHO; 2011.

2. Gravina CF, Rosa RF, Franken RA, Freitas EV, Liberman A, Rich M, et al. II Diretrizes em Cardiogeriatria da Sociedade Brasileira de Cardiologia. Arq Bras Cardiol. 2010;95(3 supl 2):1-112.

3. Simão AF, Precoma DB, Andrade JP, Correa Filho H, Saraiva JFK, Oliveira GMM, et al. I Diretriz Brasileira de Prevenção Cardiovascular. Arq Bras Cardiol. 2013;101(6 Supl 2):1-63.

4. Sociedade Brasileira de Cardiologia. I Diretriz Brasileira de Diagnóstico e Tratamento da Síndrome Metabólica. Arq Bras Cardiol. 2005;84(Supl 1):5-28.

5. Fogal AS, Ribeiro AQ, Priore SE, Franceschini SCC. Prevalência de síndrome metabólica em idosos: uma revisão sistemática. Rev Assoc Bras Nutr. 2014;6(1):29-35.

6. Vidigal FC, Bressan J, Babio N, Salas-Salvadó J. Prevalence of metabolic syndrome in Brazilian adults: a systematic review. BMC Public Health. 2013;13(1):1198.

7. Ford ES, Li C, Zhao G. Prevalence and correlates of metabolic syndrome based on a harmonious definition among adults in the US. J Diabetes. 2010;2(3):180-93.

8. Brasil. Ministério da Saúde, Secretaria de Vigilância em Saúde, Departamento de Análise de Situação de Saúde. Plano de ações estratégicas para o enfrentamento das doenças crônicas não transmissíveis (DCNT) no Brasil 2011-2022. Brasília, DF: Ministério da Saúde; 2011. young and the elderly. It is therefore suggested that studies with more representative samples of the Brazilian elderly population are carried out, including of population groups from different regions of the country, as the aging of the Brazilian population occurs in different manners, being either slow or fast depending on the level of development of the region in question.

Metabolic syndrome is related to chronic diseases, and thus constitutes an important public health problem. Determining the prevalence of this syndrome in specific groups and the general population contributes to the adoption of effective preventive measures.

9. Sá NNB, Moura EC. Fatores associados à carga de doenças da síndrome metabólica entre adultos brasileiros. Cad Saúde Pública. 2010;26(9):1853-62.

10. Grundy SM, Cleeman JI, Daniels SR, Donato KA, Eckel RH, Franklin BA, et al. Diagnosis and management of the metabolic syndrome. Circulation. 2005;112(17):2735-52.

11. Callaway CW, Chumlea WC, Bouchard C, Himes JH, Lohman TG, Martin AD, et al. Circumferences. In: Lohman TG, Roche AF, Martorell R, editors. Anthropometric standardization reference manual. Champaign, IL: Human Kinetics Books; 1988. p.39-54.

12. Associação Brasileira de Empresas de Pesquisa. Critério de Classificação Econômica Brasil: ABEP. 2008.São Paulo: ABA, ANEP, ABIPEME; 2000.

13. Haskell WL, Lee IM, Pate RR, Powell KE, Blair SN, Franklin BA, et al. Physical activity and public health: updated recommendation for adults from the American College of Sports Medicine and the American Heart Association. Circulation. 2007;116:1081-93.

14. Nelson ME, Rejeski WJ, Blair SN, Duncan PW, Judge JO, King AB, et al. Physical activity and public health in older adults: recommendation from the American College of Sports Medicine and the American Heart Association. Circulation. 2007:116:1094-105.

15. Hair JF, Black WC, Babin BJ, Anderson RE, Tatham RL. Análise de dados multivariada. $\sigma^{a}$ ed. Porto Alegre: Bookman; 2009. 
16. Farias DRE, Pereira AF, Rosa G. Síndrome metabólica na doença arterial coronariana e vascular oclusiva: uma revisão sistemática. Arq Bras Cardiol. 2010;94(6):150-78.

17. Leitão MPC, Martins IS. Prevalência e fatores associados à síndrome metabólica em usuários de Unidades Básicas de Saúde em São Paulo-SP. Rev Assoc Med Bras. 2012;58(1):60-9.

18. Huffman KM, Kraus WE. Osteoarthritis and the metabolic syndrome: more evidence that the etiology of $\mathrm{OA}$ is different in men and women. Osteoarthr Cartil. 2012;20(7):603-4.

19. Kole AK, Roy R, Kole DC. Metabolic abnormalities observed in osteoarthritis of knee: a single center experience. Apollo Med. 2015;12(4):257-9.

20. Sun DL, Wang JH, Jiang B, Li LS, Li LS, Wu L, et al. Metabolic syndrome vs. its components for prediction of cardiovascular mortality: a cohort study in chinese elderly adults. J Geriatr Cardiol. 2012;9:123-9.
21. Saad MAN, Cardoso GP, Martins WA, Velarde LGC, Cruz Filho RA. Prevalência de síndrome metabólica em idosos e concordância entre quatro critérios diagnósticos. Arq Bras Cardiol. 2014;102(3):263-9.

22. Lee S, Ko Y, Kwak C, Yim E. Gender differences in metabolic syndrome components among the korean 66-year-old population with metabolic syndrome. BMC Geriatrics. 2016;16:27.

23. Vanhoni LR, Xavier AJ, Piazza HE. Avaliação dos critérios de síndrome metabólica nos pacientes atendidos em ambulatório de ensino médico em Santa Catarina. Rev Bras Clin Med. 2012;10(2):100-5.

24. Rocha FL, Menezes TN, Melo RLP, Pedraza DF. Correlação entre indicadores de obesidade abdominal e lipídeos séricos em idosos. Rev Assoc Med Bras. 2013;59(1):48-55.

25. Joshi A. Prevalence of metabolic syndrome in subjects with osteoarthritis stratified by age and sex: a cross sectional analysis in NHANES III. Int J Comput Models Algorithms Med. 2010;1(1):61-73. 